\title{
German Bight storms analysed
}

SIR - In the debate concerning climate change due to increasing emissions of radiatively active gases into the atmosphere, many people are concerned about the possibility of an intensification of extratropical storms. Even though the International Panel on Climate Change ${ }^{1}$ took a cautious stand in this matter be-

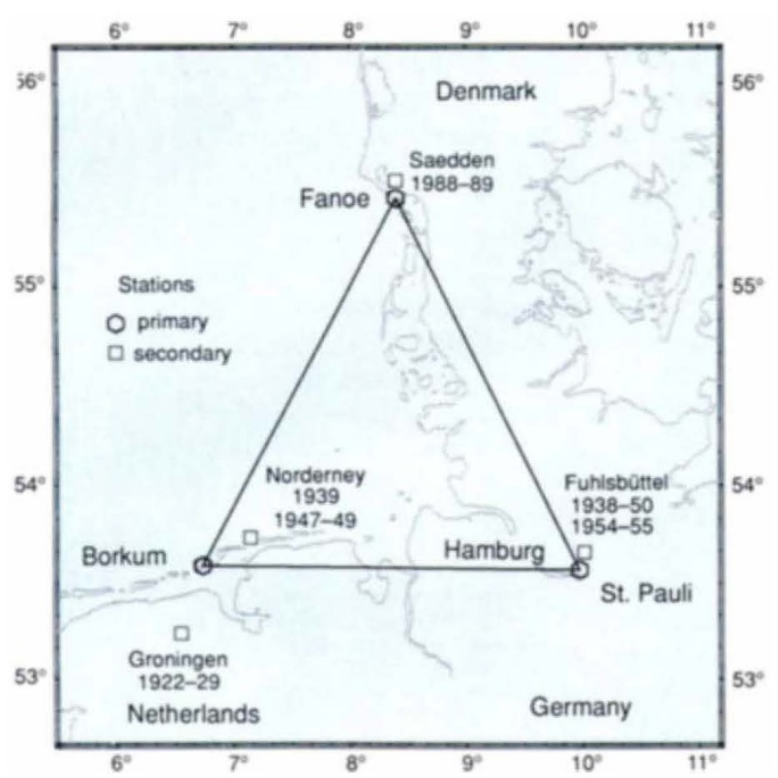

FIG. 1 Location of the meteorological stations from which pressure readings have been used to estimate geostrophic wind speed in the German Bight from 1876 to 1989.

cause of lack of evidence, a mixture of indirect evidence and misleading scientific statements has created substantial unease in the public.

Reports have been presented to the North Sea offshore oil industry about extreme waves, higher than ever previously observed. Two workshops "Climate Trends and Future Offshore Design and Operation Criteria" in Reykjavik (29-30 March 1993) and Bergen (30 November-1 December 1992) were held in which the Norwegian Weather Service brought together people from the oil industry, certifying agencies and scientists to discuss whether the wave and storm climate is in fact worsening. No definitive answers emerged - it is not possible to tell whether the extremes had become worse or if reporting systems have improved. The insurance industry has organized meetings with scientists because of the increased number of claims for storm-related damage. Newspapers in northern Europe were full of speculation about the enhanced threat of extratropical storms in the early part of 1993.

To ascertain whether the storminess really had worsened, a systematic analysis was begun at the Seewetteramt Hamburg. Identification of a trend in climatic data requires long and homogeneous time series, but homogeneous daily time series of wind for studying extreme events are rarely available because of changing procedures in observing, reporting or analysing the wind. The geostrophic wind (blowing parallel to isobars and representing the first-order approximation of the real wind) computed from pressure readings from a few stations can be regarded as a proxy for the real wind. From this model, annual frequency distributions of daily wind can be obtained for periods of 100 and more years. Any trend in the wind statistics will be reflected in these geostrophic wind statistics.

We applied this approach to the German Bight, in the southeast part of the North Sea, where three stations have reported air pressure since 1876 (Fig. 1). The resulting time series of the 1 , 10 and $50 \%$ percentiles of the annual distributions of geostrophic wind speeds (Fig. 2) stayed remarkably stationary, showing that this storm statistic has not changed in the German Bight in the past 100 years.

An alternative, and potentially more convincing, analysis would be to examine the historical weather maps and count the number of storms with a core pressure below certain thresholds. Such an analysis

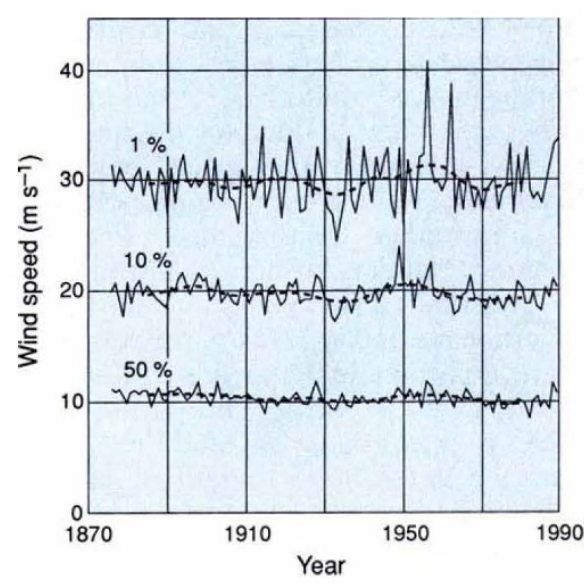

FIG. 2 Time series of the 1, 10 and $50 \%$ percentiles derived from annual distributions of daily geostrophic wind speeds in the German Bight. (The $p$ 'percentile' of a distribution $X$ is the number $x$, such that the probability of observing $X>x$ is $p$. Thus, the $1 \%$ percentile, derived from an annual ensemble of 365 samples, represents the minimum of the 3-4 largest observations.) Solid lines, annual average; broken lines, 30-year low pass. has been done, revealing a substantial increase in the number of severe storms in the North Atlantic area ${ }^{2}$. The problem with this approach is that it cannot distinguish whether changes are 'real' or whether they result from the everincreasing quality of the operational analyses arising from more and better observations, more powerful diagnostic tools and other improvements in the monitoring of the state of the troposphere. A more detailed mapping of the pressure distribution, however, automatically yields deeper lows. On the other hand, the long time-series of pressure readings suffers from no substantial inhomogeneities because the measuring instruments (mercury barometers) and reading methods have remained unchanged for more than 100 years.

Heiner Schmidt

Seewetteramt Hamburg,

20359 Hamburg, Germany

Hans von Storch

Max Planck Institut für Meteorologie,

Bundesstraße 55,

20146 Hamburg, Germany

1. Houghton, J. T., Jenkins, G. J. \& Ephraums, J. J. (eds) Climate Change. The IPCC Scientific Assessment (Cambridge University Press, 1990).

2. Schinke. H. Wiss. Z. Humboldt-Univ. Berl. 41, 17-28 (1992).

\section{Generation time and evolution}

SIR - May in News and Views ${ }^{1}$ examined the evolution of resistance to transgenic plants expressing genes for insecticidal proteins derived from the bacterium Bacillus thuringiensis. Based on a heuristic model $^{2}$, he concluded that the time required for an insect population to become resistant depends directly on the generation time of the insect but only weakly on other parameters (selection strength, initial resistance allele frequency and resistance allele dominance).

The influence of generation time on the rate of resistance evolution hinges on the relationship between generation time and the selection intensity per generation $(s)$. May's analysis assumes that $s$ is constant across species with different generation times. For insects exposed to a relatively constant dose of toxin expressed by a transgenic crop plant, this condition could be satisfied if only one developmental stage of the insect (for example, neonate larvae) is susceptible to the toxin. For insects exposed to conventional insecticides, this condition could be satisfied if the decision to apply insecticides is triggered by the density of the target pest population, and if the realized population growth rate is strongly influenced by generation time. ${ }^{3,4}$.

But it is also possible that $s$ will be a 